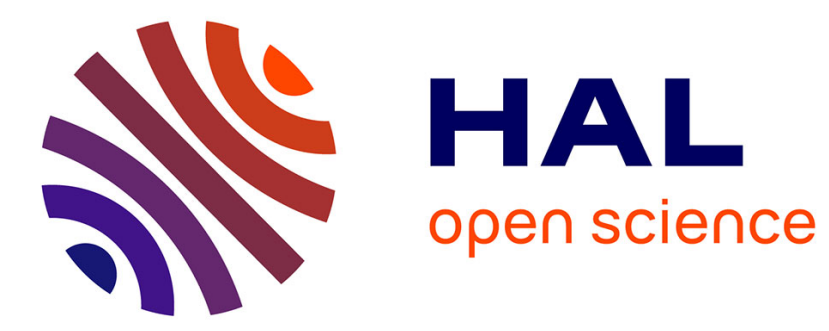

\title{
Plant wax n-alkanes trapped in soil humin by non-covalent bonds
}

Eric Lichtfouse, Patrick Wehrung, Pierre Albrecht

\section{To cite this version:}

Eric Lichtfouse, Patrick Wehrung, Pierre Albrecht. Plant wax n-alkanes trapped in soil humin by non-covalent bonds. Die Naturwissenschaften, 1998, 85 (9), pp.449-452. 10.1007/s001140050529 . hal-00193669

\section{HAL Id: hal-00193669 \\ https://hal.science/hal-00193669}

Submitted on 4 Dec 2007

HAL is a multi-disciplinary open access archive for the deposit and dissemination of scientific research documents, whether they are published or not. The documents may come from teaching and research institutions in France or abroad, or from public or private research centers.
L'archive ouverte pluridisciplinaire HAL, est destinée au dépôt et à la diffusion de documents scientifiques de niveau recherche, publiés ou non, émanant des établissements d'enseignement et de recherche français ou étrangers, des laboratoires publics ou privés. 
Revised version

Naturwissenschaften 85, 449-452, 1998.

doi: $10.1007 / \mathrm{s} 001140050529$

Correspondence: Dr. Eric Lichtfouse, INRA-CMSE-PME, 17, rue Sully, 21000 Dijon, France

Eric.Lichtfouse@dijon.inra.fr

\title{
Plant wax $n$-alkanes trapped in soil humin by non-covalent bonds
}

\author{
Eric LICHTFOUSE, Patrick WEHRUNG and Pierre ALBRECHT
}

\begin{abstract}
Soil organic matter is a very complex mixture of compounds derived from the decay of numerous living organisms. Earlier reports suggest that soil organic molecules may occur unaltered in a "bound" form, e.g. by encapsulation in the humic substances matrix or by binding involving weak forces such as $\mathrm{H}$ bonds and Van der Waals forces. This issue is relevant to the release of pesticides and other toxic compounds in waters during several years, which suggests a particular mechanim of storage of organic compounds in soil organic matter. However, so far, the mechanim of weak binding is poorly known due to possible analytical bias in the isolation of "weakly-bound" molecules, and to the lack of analytical approaches that can distinguish a "free" compound from its "weakly-bound" counterpart. Here, we analysed the ${ }^{13} \mathrm{C}$ isotope composition of plant-derived soil n-alkanes in a soil sample from an experimental field cropped 23 years with maize to label soil organic carbon. Indeed, cultivating maize, a $\mathrm{C}_{4}$ plant with ${ }^{13} \mathrm{C}$-enriched carbon, on a soil previously cropped with $\mathrm{C}_{3}$ plants, introduces ${ }^{13} \mathrm{C}$-enriched carbon in the soil. Thus maize-derived soil carbon can be distinguished from previously-cropped plant soil carbon by ${ }^{13} \mathrm{C}$ analysis. We used a recently developped analytical technique, gas chromatography - isotope ratio monitoring mass spectrometry (GC-IRMS), that allows to measure the ${ }^{13} \mathrm{C}$ isotope ratio of individual substances occurring in complex mixtures. We analysed three pools of $\mathrm{C}_{27}-\mathrm{C}_{33}$ n-alkanes in the same soil sample: 1) "free" n-alkanes that were extracted with $\mathrm{CHCl}_{3}-\mathrm{MeOH}$, 2) "bound" n-alkanes that were extracted from humin, the macromolecular part of soil organic matter, and 3) "bound" n-alkanes that were released by pyrolysis of the pre-extracted humin. Our results show that free $n$-alkanes are ${ }^{13} \mathrm{C}$-enriched by $+5.8-7.0 \%$ versus their bound n-alkanes counterparts. This finding have several implications. First, this clear isotope difference of the the same substance occurring either in free or bound form proves that there is no analytical bias such as a lack of exhautive extraction. Second, the higher ${ }^{13} \mathrm{C}$ content of free $\mathrm{n}$-alkanes evidences their higher turnover versus bound n-alkanes. Here a first-order kinetic law yields an age difference of 7 years between free and bound n-alkanes. Third, since n-alkanes are apolar compounds our results demonstrate the existence of a mechanism of weak binding involving either encapsulation or weak forces. This mechanism could explain why chemicals such as pesticides are well preserved in soil then released in waters several years after the end of their use in cropping systems. It is also relevant to the storage of organic-N compounds as possible plant nutrient precursors.
\end{abstract}

Key-words: soil organic matter; humin; plant wax n-alkane; maize; pesticide; 13C; GC-IRMS; pollutant

Note from the author: this abstract was written in 2007 for indexing in the HAL archive. 
Revised version

Naturwissenschaften 85, 449-452, 1998.

doi: $10.1007 / \mathrm{s} 001140050529$

Correspondence: Dr. Eric Lichtfouse, INRA-CMSE-PME, 17, rue Sully, 21000 Dijon, France

Eric.Lichtfouse@dijon.inra.fr

\title{
Plant wax $n$-alkanes trapped in soil humin by non-covalent bonds
}

\author{
Eric LICHTFOUSE ${ }^{*}$, Patrick WEHRUNG ${ }^{2}$ and Pierre ALBRECHT ${ }^{2}$
}

\footnotetext{
${ }^{1}$ Laboratoire Sols et Environnement, INRA/ENSAIA-INPL, BP 172, 54505 Vandoeuvre-Lès-Nancy, France.

${ }^{2}$ Laboratoire de Géochimie Organique, Institut de Chimie, 1, rue Blaise Pascal, 67008 Strasbourg Cedex, France.
}

Soil organic matter is a complex mixture of organic substances inherited from the decay of plants and micro-organisms (1). Its main part, humic substances, is made of a high molecular network (2) which is able to trap small components such as pesticides and phthalates (3). However, the binding pathways of molecules with humic substances are poorly known (3). Several molecular studies using selective chemical degradation with labelled reagents have revealed the occurrence of strong covalent bonds between xenobiotics and humic substances (4). Nonetheless, the occurrence of weak interactions at the molecular level is so far poorly known due to the lack of suitable analytical tools. Recent work involving ${ }^{13} \mathrm{C}$-NMR characterisation of ${ }^{13} \mathrm{C}$-labelled organic substances bound with humic substances strongly suggests the existence of weak bonds (5). Here, we bring indirect molecular and isotopic evidence for the occurrence of non-covalent bonds within the soil matrix. We isotopically distinguish two pools of the same molecular substances, plant wax $n$-alkanes, within the soil matrix: a first pool amenable by organic extraction of the soil, and a second, bound pool amenable by extraction of the soil humin. This sequestration of apolar substances within humin by non-covalent bonds represents a novel way of preservation of soil organic matter. Furthermore, weak binding of apolar molecules has implications in agricultural and environmental fields.

Soil organic substances can be naturally labelled by cultivation of Zea mays, a ${ }^{13} \mathrm{C}$-enriched plant, on soils previously cropped with ${ }^{13} \mathrm{C}$-depleted plants such as wheat (6). As a result, soil organic carbon becomes progressively enriched in ${ }^{13} \mathrm{C}$ due to the addition of maize carbon. At any time of maize cultivation, it is thus possible to distinguish by isotope balance the maize and wheat contributions within each soil organic component, allowing long-term turnovers to be calculated. Here, we hypothesised that if molecules are somehow trapped within the soil matrix, they should have a lower turnover than 'free' molecules, due for instance to slower bioavailability and degradation.

The free and bound fractions were isolated from a soil cropped 23 years with maize. The free fraction enriched in wax $n$-alkanes was obtained by exhaustive extraction of the soil with $\mathrm{CHCl}_{3}$ $\mathrm{MeOH}$ followed by silica gel chromatography steps (7). Humin was then isolated from the extracted soil by $\mathrm{NaOH}$ extraction to remove humic and fulvic acids, followed by $\mathrm{HF}-\mathrm{HCl}$

\footnotetext{
* author for correspondance. <lichtfouse@ensaia.u-nancy.fr>
} 
treatment to remove the main minerals (8). $\mathrm{CHCl}_{3}-\mathrm{MeOH}$ extraction of humin followed by silica gel chromatography gave the bound fraction enriched in $n$-alkanes.

Long chain $n$-alkanes show similar distributions for the free and bound soil fractions (Figure 1). This typical distribution of odd carbon-numbered $n$-alkanes implies that both fractions are derived from plant sources (9), namely maize and previously grown wheat, rather than from other living organisms. The high predominance of odd $\mathrm{C}_{27}-\mathrm{C}_{35} n$-alkanes is indeed a typical feature of plant cuticular waxes (10). Moreover, since $n$-alkanes are non-functionalized, apolar substances, a similar distribution in the free and bound fractions means clearly that plants waxes have been trapped without chemical changes, such as degradation and covalent binding. Therefore, the occurrence of these unaltered components in the humin extract shows that plant waxes can be trapped into the soil matrix by weak bonds.

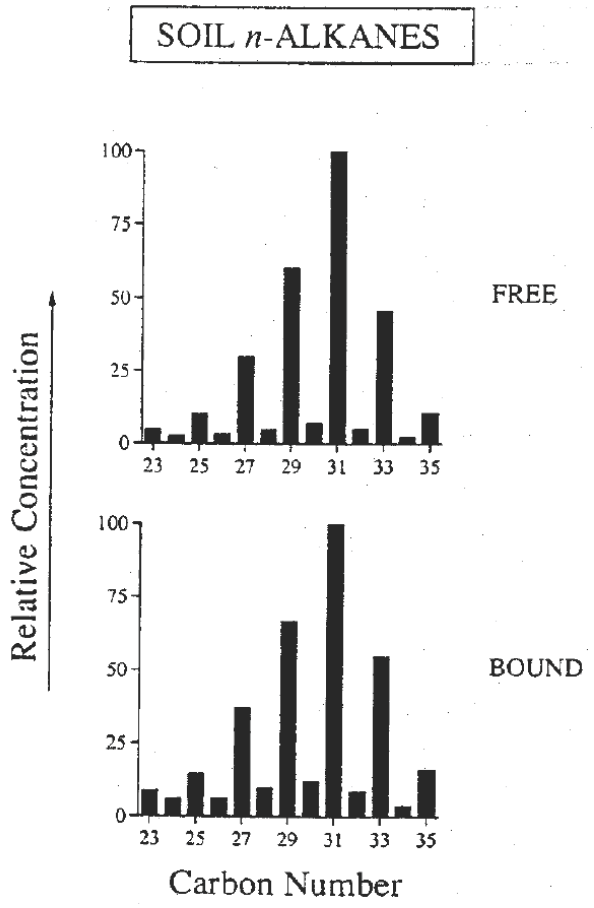

Figure 1. Distribution of $n$-alkanes from the soil extract (free) and from the humin extract (bound). Relative concentrations were measured by capillary gas chromatography coupled to a flame ionisation detector.

Nonetheless, based on these molecular observations, it could also be argued that bound $n$-alkanes result from a low efficiency of soil extraction, unless an independent information shows that bound and free soil $n$-alkanes have different properties. A such information is given by isotope analysis at the molecular level. Indeed, $\delta^{13} \mathrm{C}$ values of bound $n$-alkanes are significantly depleted in ${ }^{13} \mathrm{C}$ relatively to free $n$-alkanes (Table 1 , Figure 2). Given that each soil $n$-alkane is a mixture of ${ }^{13} \mathrm{C}$-enriched $n$-alkane from maize and ${ }^{13} \mathrm{C}$-depleted $n$-alkane from previously grown wheat, this finding implies that bound $n$-alkanes have less maize carbon than their free counterparts. Calculation of the maize contribution within individual compounds by isotope balance (5) indeed reveals that free $n$-alkanes contain $13 \pm 3 \%$ more maize derived $n$-alkanes than bound $n$-alkanes (Table 1). Bound $n$-alkanes are therefore composed of molecules that have on the average a lower turnover and a lower age than free $n$-alkanes. This age difference can be estimated by calculation 
of the cultivation time $\mathrm{t}$ at which free $n$-alkanes have had the same maize carbon content as the bound $n$-alkanes from the 23 -years maize cultivated soil, using the following first order kinetic law established for the $\mathrm{C}_{31} n$-alkane (6):

$$
\operatorname{Ln}[(100-\mathrm{M}) / 100]=-0.031 \mathrm{t}
$$

where $\mathrm{M}$ is the percentage of maize $n$-alkane within the $\mathrm{C}_{31}$ soil $n$-alkane. The calculation gives a value of 16 years, meaning that if the bound $\mathrm{C}_{31} n$-alkane of the 23 -years maize cultivated soil would derive from a once free $\mathrm{C}_{31} n$-alkane, then the trapping has occurred 7 years earlier on the average.

Table $1 . \delta^{13} \mathrm{C}$ values of $n$-alkanes and maize $\mathrm{C}$ content

\begin{tabular}{lccccccc} 
C nb. & $\delta_{0}$ & $\delta_{\mathrm{m}}$ & $\delta_{\text {free }}$ & $\delta_{\text {bound }}$ & $\mathrm{M}_{\text {free }}$ & $\mathrm{M}_{\text {bound }}$ & $\Delta \mathrm{M}$ \\
$(\%)$ & $(\%)$ & $(\%)$ & $(\%)$ & $(\%)$ & & & \\
\hline 27 & -33.0 & -19.1 & -24.0 & -26.0 & 64.7 & 50.4 & 14.3 \\
29 & -35.7 & -18.4 & -28.3 & -30.0 & 42.8 & 32.9 & 9.9 \\
31 & -35.7 & -20.6 & -28.1 & -29.7 & 50.3 & 39.7 & 10.6 \\
33 & -33.7 & -22.2 & -25.6 & -27.6 & 70.4 & 53.0 & 17.4
\end{tabular}

Isotopic compositions are expressed in per mil as $\delta^{13} \mathrm{C}$ values relative to the Pee Dee Belemnite standard : $\delta^{13} \mathrm{C}=$ $\left[\left({ }^{13} \mathrm{C} /{ }^{12} \mathrm{Csample}-{ }^{13} \mathrm{C} /{ }^{12} \mathrm{Cstd}\right) /\left({ }^{13} \mathrm{C} /{ }^{12} \mathrm{Cstd}\right)\right] \times 10^{3}$. $\delta_{0}$ refers to soils from the Boigneville experimental field (6) cultivated only with wheat. $\delta_{\mathrm{m}}$ refer to leaf maize cuticular waxes (13). 'Free' and 'bound' refer to $n$-alkanes occurring respectively in the soil extract and humin extract of the soil from the field cultivated 23 years with maize. $\mathrm{M}$ is the percentage of maize derived $n$-alkane in each soil $n$-alkane (6) : $\left.\mathrm{M}=100 .\left(\delta_{\text {soil }}-\delta_{0}\right) / \delta_{\mathrm{m}}-\delta_{0}\right)$, where $\delta_{\text {soil }}$ is either $\delta_{\text {free }}$ or $\delta$ bound. $\Delta \mathrm{M}=\mathrm{M}_{\text {free }}-\mathrm{M}_{\text {bound }}$. Noteworthy, the good accuracy of such calculations is confirmed by a recent study showing the absence of carbon isotope fractionation of plant $n$-alkanes in a 23 -year field decomposition experiment (14).

Detailed experimental procedures are described elsewhere $(6,7,8)$. The Boigneville soil is a Hapludalf developed on loess containing $22 \%$ clay, $1 \%$ organic carbon, and $0.1 \%$ organic nitrogen. Typically, $0-30 \mathrm{~cm}$ cores, corresponding to the ploughed horizon, were sampled at random position in the fields, mixed, dried at $20^{\circ} \mathrm{C}$, sieved to $2 \mathrm{~mm}$ to remove coarse debris, then finely ground; $100 \mathrm{~g}$ were thoroughly extracted with $\mathrm{CHCl}_{3}-\mathrm{MeOH} 3 / 1 \mathrm{v} / \mathrm{v}$.

Isolation of free $n$-alkanes : the extract $(10.5 \mathrm{mg})$ was fractionated into acid and neutral fractions by passage through silica gel impregnated with $\mathrm{KOH}$ followed by $\mathrm{HCO}_{2} \mathrm{H}$ acidification. The neutral fraction was fractionated into polar, alcohol, ketone, and hydrocarbon-ester fractions by silica-gel thin layer chromatography using $\mathrm{CH}_{2} \mathrm{Cl}_{2}$ as developer and 1,2:3,4-dibenzanthracene, friedelin, and cholesterol as reference compounds. Hydrocarbon-ester fractions were fractionated into alkane-alkene $(0.4 \mathrm{mg}$, including the free $n$-alkanes), aromatic, and ester fractions by silica-gel thin layer chromatography using $n$-hexane as developer and 1-phenyldodecane, 2-methylphenanthrene, and 1,2:3,4dibenzanthracene as reference compounds.

Isolation of bound $n$-alkanes : the $\mathrm{CHCl}_{3}-\mathrm{MeOH}$ extracted soil was treated with $\mathrm{NaOH} 0.1 \mathrm{M}$ to remove fulvic and humic acids, then with $\mathrm{HF} / \mathrm{HCl}$ to give $1.34 \mathrm{~g}$ of concentrated humin. The humin extract $(28,1 \mathrm{mg})$ and the alkanealkene fraction $(8.5 \mathrm{mg}$, including the bound $n$-alkanes) were separated from the humin as described above.

Isotopic analyses of individual $n$-alkanes from alkane-alkene fractions ( 3 to 4 replicates, deviation $\leq 0.3 \%$ ) were carried out under a continuous helium flow using a Hewlett Packard gas chromatograph coupled to a $\mathrm{CuO}$ furnace and a Finigan Mat 252 isotope ratio mass spectrometer. Accurate isotope values were measured by comparison with $\mathrm{CO}_{2}, 5 \alpha$-androstane and $n$-tetracontane standards. 


\section{SOIL $n$-ALKANES}

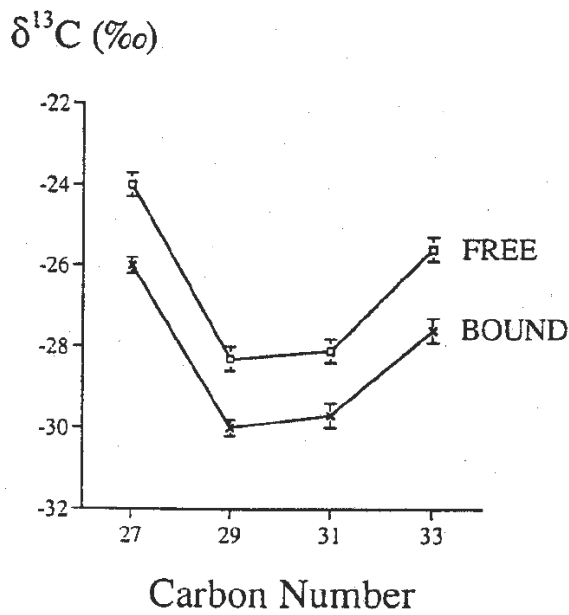

Figure 2. $\delta^{13} \mathrm{C}$ values of $n$-alkanes from the soil extract (free) and from the humin extract (bound).

Furthermore, we have also studied another bound alkane fraction released by $600^{\circ} \mathrm{C}$ pyrolysis of the extracted humin. Again, we observed the odd-carbon numbered predominance of $\mathrm{C}_{27} \mathrm{C}_{33} n$ alkanes, a typical feature indicating the input of plant waxes (10). These pyrolysate $n$-alkanes have also been analysed for ${ }^{13} \mathrm{C}$ compositions. The data show that $\delta^{13} \mathrm{C}$ values of pyrolysate $n$-alkanes and of humin extract $n$-alkanes are very close (Table 2). A such finding clearly confirm the occurrence of an older pool of wax $n$-alkane trapped in humin. Moreover, it means that a part of apolar organic molecules sequestred into humin can not be released by regular solvent extraction.

Table 2. $\delta^{13} \mathrm{C}$ values of bound $n$-alkanes from $\mathrm{CHCl}_{3}-\mathrm{MeOH}$ humin extract, and from the $600^{\circ} \mathrm{C}$ pyrolysate of the extracted humin.

\begin{tabular}{ccc} 
CARBON & $\begin{array}{c}\text { Humin extract } \\
\delta_{\text {bound }} \\
(\% o)\end{array}$ & $\begin{array}{c}\text { Humin pyrolysate } \\
\delta_{\text {bound }} \\
(\% o)\end{array}$ \\
NUMBER & & \\
\hline 27 & -26.0 & -26.5 \\
29 & -30.0 & -29.5 \\
31 & -29.7 & -29.7 \\
33 & -27.6 & -27.8 \\
\hline
\end{tabular}

Plant wax $n$-alkanes may be enclosed within the soil matrix by different processes involving van der Waals forces. First, wax $n$-alkanes could be adsorbed on soil humic substances by hydrophobic-hydrophobic interactions (3), as suggested by the occurrence of $n$-alkane in humic acids (11). Indeed, in view of the high polarity of the soil aqueous solution, apolar substances are prone to absorption on the hydrophobic surfaces of the organic matter (3). This hypothesis is in agreement with the fact that the amount of pesticide bound residues is increasing with organic 
matter content (3). Alternatively, plant wax $n$-alkanes could be encapsulated as inclusion compounds in organo-mineral lattices during humification processes. Here, there is also no binding between the $n$-alkane guest and the soil host, except van der Waals forces. Whatever mode of sequestration, our findings show unambiguously the existence of a pool of apolar molecules trapped by non-covalent binding.

Several implications may be foreseen from the occurrence of weakly bound apolar substances in soils. Firstly, it gives evidence for a novel and alternative process of formation of soil organic matter which involves preservation by non covalent binding. Indeed, it contrasts sharply with other possible processes such as polycondensation of small molecules (3) and selective preservation of resistant biopolymers (8). Moreover, our findings are in agreement with recent ${ }^{13} \mathrm{C}$-NMR studies showing non-covalent interactions between fulvic acids and acenaphthenone (5). Secondly, it has been shown that lipids act as cements of soil mineral aggregates (12), thus preventing soil erosion by intense cropping. If that is the case, then keeping a high pool of trapped lipids, later released by ploughing, may favour sustainable agricultural practices. Thirdly, a broad range of xenobiotics including pesticides (3), polychlorobiphenyls (3) and aromatic hydrocarbons (7) are highly hydrophobic. It is therefore expected that such compounds would be trapped within the soil matrix in the similar way as $n$-alkane by non covalent binding. Trapping by non covalent bonds may thus lead to the temporary storage of unaltered xenobiotics within the soil matrix.

\section{REFERENCES}

(1) Schnitzer M. Soil Science 151, 41 (1991).

(2) Ogner, G. \& Schnitzer, M. Science 170, 317 (1970). Hayes, M.B.H., MacCarthy, P., Malcolm, R.L. \& Swift, R.S. (Eds.) Humic Substances II (Wiley, 1989).

(3) Bollag, J.-M. \& Loll, M.J. Experientia 39, 1221 (1983). Roberts, T.R. Pure \& Appl. Chem. 56, 945 (1984).

(4) Richnow, H.H., Seifert, R., Hefter, J., Kästner, M., Mahro, B. \& Michaelis, W. Org. Geochem. 22, 671 (1994). Michaelis, W., Richnow, H.H. \& Seifert, R. Naturwissenschaft. 82, 139 (1995).

(5) Nanny, M.A., Bortiatynski, J.M. \& Hatcher, P.G. Environ. Sci. Technol. 31, 530 (1997).

(6) Lichtfouse, E. Naturwissenschaft. 84, 23 (1997).

(7) Lichtfouse, E., Budzinski, H., Garrigues, Ph. \& Eglinton, T.I. Org. Geochem. 26, 353 (1997).

(8) Lichtfouse, E., Chenu, C. \& Baudin, F. Org. Geochem. 25, 263 (1996).

(9) Lichtfouse, E. \& Eglinton, T.I. Org. Geochem. 23, 969 (1995).

(10) Eglinton, G. \& Hamilton, R.J. Science 156, 1322 (1967).

(11) Schnitzer, M. \& Neyroud, J.A. Fuel 54, 17 (1975).

(12) Jambu, P., Fustec, E. \& Jacquesy, R. Sci. Sol 4, 229 (1978).

(13) Lichtfouse, E. Tetrahedron Lett. 36, 529 (1995).

(14) Huang, Y., Eglinton, G., Ineson, P., Latter, P.M., Bol, R. \& Harkness, D.D. Org. Geochem. 26, 497 (1997). 